\title{
Ordenamiento Territorial de Bosques Nativos: Resultados de la Zonificación realizada por provincias del Norte argentino
}

\author{
María Agustina García Collazo ${ }^{1, \bowtie}$, Amalia Panizza² \& José María Paruelo 3 \\ 1. Departamento de Métodos Cuantitativos y Sistemas de Información. Facultad de Agronomía, Universidad de Buenos Aires. \\ 2. Facultad de Agronomía de Buenos Aires. Departamento de Métodos Cuantitativos y Sistemas de Información. 3. Facultad \\ de Agronomía (UBA), Laboratorio de Análisis Regional y Teledetección, IFEVA, CONICET, Departamento de Métodos
}

Cuantitativos y Sistemas de Información

\begin{abstract}
Resumen. Argentina cuenta con varias experiencias de ordenamiento territorial (OT) pero hasta el momento no ha sancionado una ley integral. Uno de los principales antecedentes es el ordenamiento territorial de los bosques nativos (OTBN) a través de la ley 26331, sancionada en 2007. El objetivo de este trabajo fue evaluar las experiencias de zonificación en el marco de esta ley de las provincias de Santiago del Estero, Chaco, Formosa y Salta. Se analizó la aplicación de los 10 criterios de sustentabilidad ambiental contemplados por la ley y se compararon cuantitativamente los mapas de zonificación resultantes del proceso de OTBN en las áreas limítrofes. La interpretación de los criterios de sustentabilidad ambiental ha sido dispar entre provincias debido, en parte, a que la información de base utilizada no tiene el mismo nivel de detalle. Salta y Chaco consideraron mayor detalle en estos criterios mientras que Santiago del Estero y Formosa utilizaron información con un nivel de detalle menor. La comparación de la categorización de bosques entre provincias colindantes muestra que la mayor concordancia en las categorías asignadas se observa en los límites de Santiago del Estero y Chaco (58.3\%). El grado de concordancia entre los restantes pares de provincias colindantes resultó considerablemente menor: $24.76 \%$ entre Chaco y Salta; $20.65 \%$ entre Formosa y Salta; $10.54 \%$ entre Chaco y Formosa y $1.28 \%$ entre Salta y Santiago del Estero. Los resultados sugieren que las zonificaciones no han resultado consistentes debido al bajo nivel de concordancia en la categorización de sus bosques.
\end{abstract}

[Palabras clave: Ley de bosques nativos, Plan de ordenamiento territorial, criterios de sustentabilidad ambiental, categorías de conservación]

\begin{abstract}
Aвstract. Native Forest Land Management: Zoning results performed by North argentinean provinces: Argentina has several experiences on Land Planning, but so far there is not an integral normative. A key background experience is the land use planning of native forest act (26331) from 2007.The aim of this study was to evaluate the experiences of zoning of the provinces of Santiago del Estero, Chaco, Formosa and Salta in the context of this act. We characterize the way the 10 criteria of environmental sustainability were considered by the four provinces, and we quantitatively compared the zoning maps on the provincial boundaries. The interpretation of the criteria of environmental sustainability differed, in part, because the different provinces did not use the same level of detail. Salta and Chaco considered a higher level of detail on these criteria than the rest. The comparison of the way forests were categorized showed that the highest concordance corresponded to the Santiago del Estero - Chaco border (58.3\%). All the other pairs of neighbor provinces presented a significantly lower concordance: $24.76 \%$ between Chaco and Salta, $20.65 \%$ between Formosa and Salta, $10.54 \%$ between Chaco and Formosa and $1.28 \%$ between Salta and Santiago del Estero. Our results suggest that the zoning has not been consistent due to the low agreement on the categorization of forests among provinces.
\end{abstract}

[Keywords: Native forests act, land use planning, environmental sustainability criteria, conservation categories]

\section{INTRODUCCIÓN}

El proceso de pérdida de bosques nativos en Argentina se ha acelerado durante los últimos 10 años. Según datos de la UMSEF (2007) entre 1987-1998 y 1998-2002 se deforestaba a una tasa de 180000 y 235100 ha/año, respectivamente. La mayor tasa de deforestación ocurrió en el norte del país, particularmente en Santiago del Estero, Salta y Chaco. Durante el período 2002-2006, la tasa de deforestación continuaba en aumento: $123 \%$ en Salta, $83 \%$ en Santiago del Estero, 56\% en Formosa y 14\% en Chaco,

$\triangle$ garciaco@agro.uba.ar por encima del periodo anterior (Volante et al. 2006, 2012; UMSEF 2007).

En 2007 se sancionó la Ley de Presupuestos Mínimos de Protección Ambiental de los Bosques Nativos (Ley 26331). Esta ley establece "los presupuestos mínimos de protección ambiental para el enriquecimiento, la restauración, conservación, aprovechamiento y manejo sostenible de los bosques nativos y de los servicios ambientales que éstos brindan a la sociedad" (ver Apéndice I). En la ley se mencionan como objetivos: a) promover la

Editora Asociada: Ana Cingolani Recibido: 6 de noviembre de 2012; Fin de arbitraje: 18 de febrero 2013; Revisión recibida: 2 de julio; Aceptado: 2 de julio.. 
Tabla 1. Criterios de sustentabilidad ambiental considerados para la definición de las categorías de conservación de acuerdo a la Ley 26331.

Table 1. Environmental sustainability criteria considered for the definition of conservation categories according to Law 26331.

\begin{tabular}{ll}
\hline Criterio de sustentabilidad ambiental & Breve descripción \\
\hline 1. Superficie & Tamaño mínimo de hábitat para mantener poblaciones de fauna y flora. \\
2. Vinculación con otras comunidades & Preservación de gradientes ecológicos completos.
\end{tabular}

2. Vinculación con otras comunidades Preservación de gradientes ecológicos completos.

naturales (no boscosas)

3. Vinculación con áreas protegidas e Complementariedad de las unidades del paisaje y mantenimiento de integración regional

4. Existencia de valores biológicos sobresalientes

5. Conectividad entre ecorregiones conectividad con áreas protegidas.

Especies raras o poco frecuentes.

6. Estado de conservación

7. Potencial forestal

Corredores boscosos y riparios garantizan conectividad.

Tipo de uso, disturbios, contexto en que está inmerso.

Disponibilidad actual y capacidad productiva. Determinada por estructura del bosque, renovales valiosos e individuos de valor comercial.

8. Potencial de sustentabilidad agrícola Factibilidad de implementar actividades económicamente sostenibles en el largo plazo.

9. Potencial de conservación de cuencas

Posición estratégica: protección de nacientes, bordes de cauces de agua, franja de bosques nublados, humedales, áreas de grandes pendientes, etc.

10. Valor que las Comunidades

Indígenas y Campesinas dan a los BN

Uso que pueden hacer del bosque para su supervivencia y mantener su cultura. Considerando la situación de tenencia de la tierra.

conservación mediante el Ordenamiento Territorial de Bosques Nativos (OTBN) y la regulación de la expansión de la frontera agropecuaria y de cualquier otro cambio de uso del suelo; b) implementar las medidas necesarias para regular y controlar la disminución de la superficie de bosques nativos existentes, tendiendo a lograr una superficie perdurable en el tiempo; c) mejorar y mantener los procesos ecológicos y culturales en los bosques nativos que beneficien a la sociedad; d) hacer prevalecer los principios precautorio y preventivo, manteniendo bosques nativos cuyos beneficios ambientales o los daños ambientales que su ausencia generase, aun cuando no puedan demostrarse con las técnicas disponibles en la actualidad; e) fomentar las actividades de enriquecimiento, conservación, restauración, mejoramiento y manejo sostenible de los bosques nativos.

Las provincias deben realizar, en un plazo establecido y mediante un proceso participativo, el OTBN utilizando 10 criterios de sustentabilidad ambiental (Tabla 1), con el fin de establecer diferentes categorías de conservación del bosque (Tabla 2). Las jurisdicciones que implementan la ley son compensadas económicamente de forma anual, a través del Fondo Nacional para el Enriquecimiento y la Conservación de los Bosques Nativos (B.O. 31595 2009).

En el contexto de una gran expansión del área agrícola a partir de desmontes (Zak et al. 2004; Grau et al. 2005; Paruelo et al. 2005; Aizen et al. 2009) esta ley es la primera experiencia a nivel nacional de ordenamiento territorial que regula cambios en el uso del suelo. Sin embargo, la ley ha generado controversias políticas y técnicas. Desde el punto de vista político, introduce el tema de "pago por servicios ambientales", un tema complejo y polémico a nivel nacional e internacional que ha sido revisado y discutido (Paruelo 2011; Balvanera et al. 2012; Viglizzo et al. 2012). Los procesos de zonificación a nivel provincial han dado lugar a debates tanto desde el punto de vista técnico como político (Seghezzo et al. 2011). Por otro lado, al yuxtaponer los mapas con las zonificaciones del bosque no hay coincidencia

Tabla 2. Categorías de conservación establecidas en la Ley 26331 y sus características.

Table 2. Conservation categories established by Law 26331 and its main characteristics.

\begin{tabular}{ll}
\hline Categoría & Característica \\
\hline I (rojo) & $\begin{array}{l}\text { Sectores de muy alto valor de conservación que no deben desmontarse ni utilizarse para la extracción } \\
\text { de madera y que deben mantenerse como bosque. Incluye reservas naturales y sus áreas circundantes } \\
\text { que tengan valor biológico sobresaliente, y/o sitios que protejan cuencas hídricas de importancia } \\
\text { (nacientes de ríos y arroyos). }\end{array}$ \\
II (amarillo) & $\begin{array}{l}\text { Sectores de alto o medio valor de conservación, que pueden estar degradados pero que si se los restaura } \\
\text { pueden tener un valor alto de conservación. Estas áreas no pueden desmontarse, pero podrán ser } \\
\text { sometidas a: aprovechamiento sostenible, turismo, recolección e investigación científica. }\end{array}$ \\
III (verde) & $\begin{array}{l}\text { Sectores de bajo valor de conservación que pueden transformarse parcialmente o en su totalidad, } \\
\text { con la previa realización de una Evaluación de Impacto Ambiental. }\end{array}$ \\
\hline
\end{tabular}




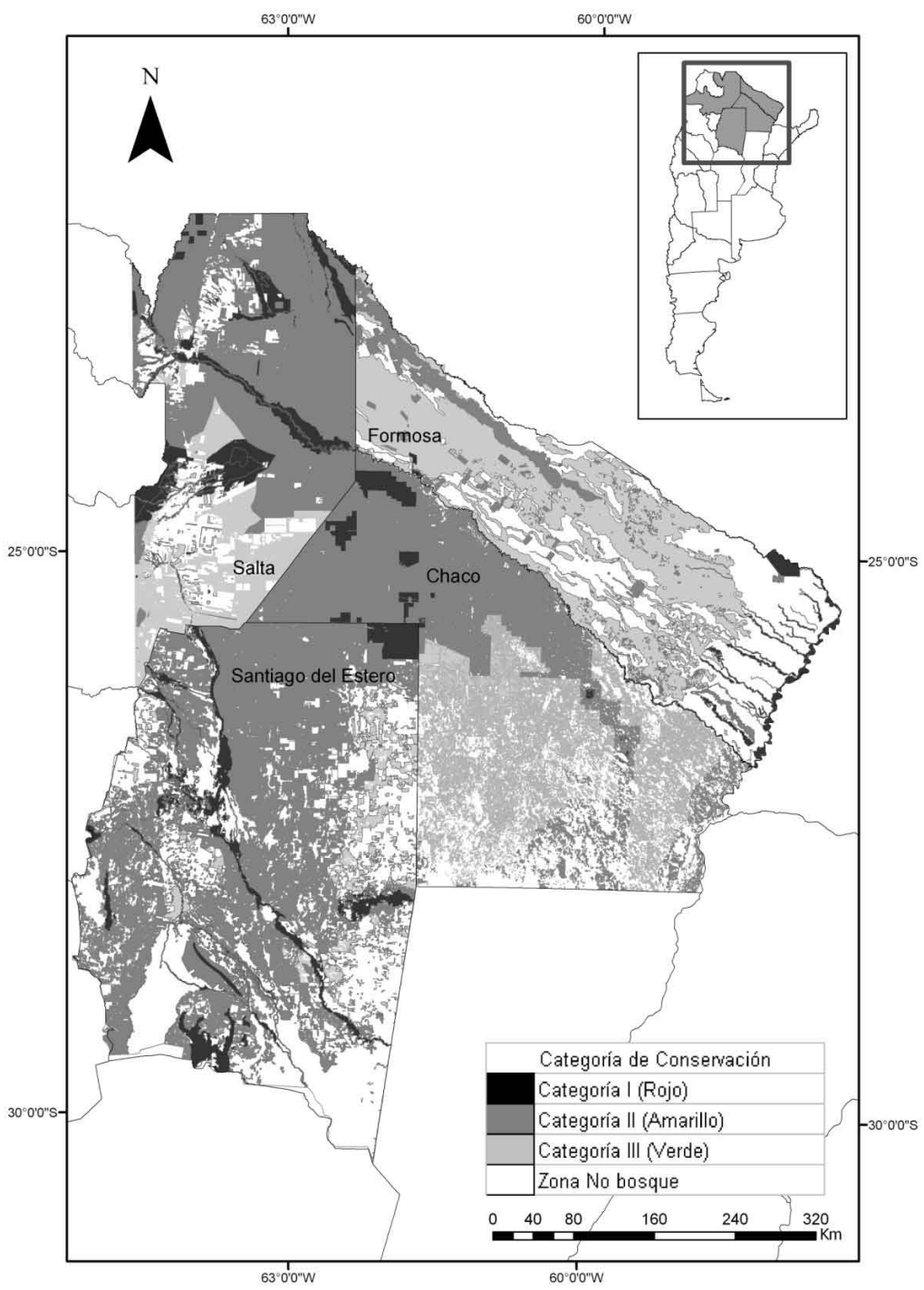

Figura 1. Zonificación de la ley 26331 de OTBN para las provincias de Santiago del Estero, Chaco, Formosa y Salta (Fuente: Apéndice II).

Figure 1. Zoning of the law 26331 for the provinces of Santiago del Estero, Chaco, Formosa and Salta (Source: Appendix II). entre las categorías de conservación a lo largo de los límites provinciales (Figura 1). Por lo tanto, la implementación de esta ley ha puesto en debate la interpretación de los 10 criterios de sustentabilidad ambiental establecidos en ella y el principio de cooperación entre las provincias establecido dentro de la Ley General del Ambiente (25675).

El objetivo de este trabajo fue analizar y evaluar las experiencias de OTBN asociadas a la Ley 26331 de algunas provincias del Noroeste Argentino (Santiago del Estero, Chaco, Formosa y Salta). Para ello se identificó cómo los criterios establecidos fueron implementados y se realizó una comparación cuantitativa de los mapas de zonificación resultantes del proceso de OTBN en las áreas limítrofes. Específicamente se buscó responder a una serie de interrogantes. 1. ¿En qué información se basó la zonificación?
2. ¿Difiere entre provincias la interpretación de los criterios establecidos por la ley? 3. ¿Cuál ha sido el grado de acuerdo existente entre la zonificación de provincias vecinas? 4. ¿Es posible identificar diferencias significativas en la categorización de los bosques nativos a ambos lados del límite provincial?

\section{MAteriales y Métodos}

El estudio se realizó en cuatro provincias del norte de la República Argentina: Salta, Santiago del Estero, Chaco y Formosa. Se analizaron dos aspectos, por un lado se compararon cualitativamente los criterios utilizados para la zonificación de bosques nativos a fin de responder a los interrogantes 1 y 2 planteados en la introducción. Para determinar cómo han sido adoptados los diferentes criterios de sustentabilidad ambiental establecidos dentro de la ley nacional y qué fuentes bibliográficas se emplearon para su determinación se recopilaron y analizaron los informes técnicos proporcionados por cada 
provincia y las respectivas leyes provinciales. Por otro lado, para responder los interrogantes 3 y 4 se realizó una comparación cuantitativa de los mapas de zonificación mediante la utilización de un índice que compara las categorías del OTBN asignadas en las áreas limítrofes de cada provincia, usando un Sistema de Información Geográfico (ArcGIS 9.3).

Para definir el área de comparación se ubicaron de manera sistemática puntos sobre el límite provincial a una distancia de $2000 \mathrm{~m}$ entre sí usando la extensión Hawth's Analysis del sistema ArcGis. En torno de esos puntos se generaron círculos (buffers) de $1000 \mathrm{~m}$ de radio de manera tal que cada semicírculo cubriera cada lado del límite provincial. Con este índice se procuró evaluar la ocurrencia de la misma clase a ambos lados del límite en todos los sitios donde se definieron áreas buffer. Existe la posibilidad de que ambos semicírculos tengan iguales proporciones para una o más de las categorías de conservación pero no haya continuidad entre ellas a través del límite provincial. Sin embargo, el pequeño diámetro de los círculos utilizados minimiza la probabilidad de incurrir en este error de evaluación. En el siguiente paso, se superpuso el área de los semicírculos con el mapa vectorial de zonificación de cada provincia. De esta manera se generó un archivo que incluye la siguiente información: provincia, categoría de conservación, área de cada polígono (área total del semicírculo y área total de cada categoría de conservación que lo compone) e identificación de cada buffer. La tabla de datos de este archivo se exportó a una planilla de cálculo. Los semicírculos enfrentados están identificados con la misma identificación de manera de poder operar con ellos. Las superficies ocupadas por los semicírculos no necesariamente eran iguales entre provincias dada la irregularidad de los límites provinciales, pero las diferencias promedio fueron del $9.7 \%$, mientras que la frecuencia relativa de valores extremos (diferencias mayores al 30\%) fue del 9.96\%.

Se construyó un índice basado en la clase mayoritaria. Este índice compara la categoría de conservación de la clase mayoritaria de una determinada superficie (semicírculo) a cada lado del límite provincial. Para cada semicírculo, se asignó el valor de la clase mayoritaria. Se asignó un valor de 1 a aquellos semicírculos donde la clase mayoritaria correspondía a la categoría de conservación I (rojo); un valor de 2 a aquellos donde la clase mayoritaria correspondía la categoría II (amarillo); un valor de 3 a aquellos donde la clase mayoritaria correspondía a la categoría III (verde) y un valor de 10 a aquellos donde la clase mayoritaria correspondía a zonas de "no bosque".

A partir de estos valor, se calculó el índice I como

$$
\mathrm{I}_{\mathrm{ijk}}=\mathrm{V}_{\mathrm{ij}}-\mathrm{V}_{\mathrm{ik}}
$$

donde $\mathrm{V}$ es la categoría de conservación de la clase mayoritaria asignada previamente a la provincia $j$ respecto a la provincia k de los semicírculos con igual número de identificación i. Los distintos pares de provincias colindantes $\mathrm{j}-\mathrm{k}$ analizados corresponden a Santiago del Estero-Chaco; Chaco-Formosa; Formosa-Salta; Chaco-Salta y Santiago del EsteroSalta. Aquellos círculos donde la clase dominante no fuera bosque (cuando uno o ambos semicírculos tenían un valor de 10) fueron descartados de los subsiguientes análisis estadísticos (valores del índice inferiores a -3 ó superiores a 3 provenientes de unidades con las siguientes clases mayoritarias de los distintos pares de provincias colindantes: 101, 10-2, 10-3, 1-10, 2-10, 3-10; y valores del índice igual a cero provenientes de unidades que a ambos lados es "no bosque").

Las diferencias en la frecuencia de valores del índice I entre los distintos pares de provincias colindantes se evaluaron mediante una prueba de Chi Cuadrado (Devore 2003). Se evaluó la correspondencia entre las frecuencias observadas y una distribución esperada: $\pi 1=0.05 ; \pi 2=0.90 \mathrm{y}$ $\pi 3=0.05$. Donde $\pi 1$ es igual a la probabilidad de la cola izquierda (valor del índice de -2 y -1), $\pi 2$ probabilidad de que el valor del índice sea cero, $\pi 3$ probabilidad de la cola derecha (valor del índice 1 y 2$)$.

Tabla 3. Nivel de transformación admisible dentro de cada categoría de conservación prevista por la ley de OTBN para las provincias analizadas.

Table 3. Level of admissible transformation within each conservation category prescribed by the law of OTBN for the provinces analyzed.

\begin{tabular}{|c|c|c|c|}
\hline \multirow[t]{2}{*}{ Provincia } & \multicolumn{3}{|c|}{ Categoría de conservación } \\
\hline & (I ) Rojo & (II) Amarillo & (III) Verde \\
\hline Salta & $\begin{array}{l}\text { No puede } \\
\text { transformarse }\end{array}$ & Uso sustentable (Artículo 4, Ley 26331) & Puede transformarse en su totalidad. \\
\hline Chaco & $\begin{array}{l}\text { No puede } \\
\text { transformarse }\end{array}$ & $\begin{array}{l}\text { Permite: } 20 \% \text { desmonte y } 50 \% \\
\text { silvopastoril. Conserva } 30 \%\end{array}$ & $\begin{array}{l}\text { Conservar de } 10 \% \text { a } 50 \% \text { dependiendo del } \\
\text { tamaño del lote y si genero clausuras o reservas. }\end{array}$ \\
\hline $\begin{array}{l}\text { Santiago del } \\
\text { Estero }\end{array}$ & $\begin{array}{l}\text { No puede } \\
\text { transformarse }\end{array}$ & $\begin{array}{l}\text { Permite } 10 / 20 \% \text { desmonte (para } \\
\text { forraje); hasta } 40 \% \text { manejo silvopastoril } \\
50 / 40 \% \text { manejo de bosque; } \\
\text { conservando }<50 \%\end{array}$ & Conservar 30/40\% como macizo \\
\hline Formosa & $\begin{array}{l}\text { No puede } \\
\text { transformarse }\end{array}$ & Uso sustentable (Artículo 4, Ley 26331) & $\begin{array}{l}\text { Según zona el nivel de transformación permitido } \\
\text { resulta: Central/Oriental: } 60 \% \text {; Corredor/ } \\
\text { Occidental: } 20 \% \text {. Además depende del grupo } \\
\text { fisonómico involucrado. }\end{array}$ \\
\hline
\end{tabular}




\section{RESUltados}

Los antecedentes en los cuales se apoyó el proceso de Ordenamiento Territorial de Bosques Nativos en cada provincia fueron diferentes. Chaco y Formosa poseen una ley de bosques (2386 y 488 respectivamente) que clasifica a los bosques nativos y reglamenta su aprovechamiento. Formosa dispone, además, del Programa de Ordenamiento Territorial de Formosa (POT-For, Ley Provincial 1552/2011 expediente 76520-R-10). Santiago del Estero posee una ley de conservación y uso múltiple de áreas forestales (6841) que establece una zonificación con once categorías y los porcentajes de desmonte permitidos. Por otro lado, Salta carece de una Ley de Bosques y el proceso se apoyó en las leyes provinciales de Reservas Forestales (5360), de protección del medio ambiente (7070) y de áreas protegidas (7107).

La autoridad de aplicación de la ley de OTBN también varió entre provincias. En Santiago del Estero es responsable el Consejo Provincial de Bosque que a diferencia del resto de las provincias está integrado por el Ministerio de Producción, Recursos Naturales, Forestación y Tierras, la Facultad de Ciencias Forestales (UNSE), la Facultad de Agronomía

Tabla 4. Especificaciones acerca de cómo han sido considerados los criterios de sustentabilidad ambiental por las provincias de Santiago del Estero, Chaco, Formosa y Salta.

Table 4.Specifications about how the environmental sustainability criteria have been considered for the provinces of Santiago del Estero, Chaco, Formosa and Salta.

\begin{tabular}{|c|c|c|c|c|}
\hline Criterio & $\begin{array}{l}\text { Santiago del } \\
\text { Estero }\end{array}$ & Chaco & Formosa & Salta \\
\hline 1. Superficie & No especificado & Áreas protegidas & No especificado & Conectividad entre bloques \\
\hline $\begin{array}{l}\text { 2. Vinculación } \\
\text { con otras } \\
\text { comunidades } \\
\text { naturales }\end{array}$ & No especificado & Biodiversidad & No especificado & Fisonomía de la vegetación \\
\hline $\begin{array}{l}\text { 3. Vinculación } \\
\text { con áreas } \\
\text { protegidas } \\
\text { existentes e } \\
\text { integración } \\
\text { regional }\end{array}$ & $\begin{array}{l}\text { Amortiguación } \\
\text { de AP }\end{array}$ & Red de áreas protegidas & No especificado & Amortiguación de AP \\
\hline $\begin{array}{l}\text { 4. Existencia } \\
\text { de valores } \\
\text { biológicos } \\
\text { sobresalientes }\end{array}$ & $\begin{array}{l}\text { Cuencas de } \\
\text { especial interés }\end{array}$ & $\begin{array}{l}\text { Presencia de especies } \\
\text { clave }\end{array}$ & $\begin{array}{l}\text { Zonificación de } \\
\text { la provincia }\end{array}$ & $\begin{array}{l}\text { Elementos/sistemas biológicos de } \\
\text { especial interés }\end{array}$ \\
\hline $\begin{array}{l}\text { 5. Conectividad } \\
\text { entre } \\
\text { ecorregiones }\end{array}$ & $\begin{array}{l}\text { Corredores } \\
\text { riparios }\end{array}$ & Corredores riparios. & $\begin{array}{l}\text { Corredores } \\
\text { riparios }\end{array}$ & Corredores boscosos \\
\hline $\begin{array}{l}\text { 6. Estado de } \\
\text { conservación }\end{array}$ & No especificado & No especificado & No especificado & $\begin{array}{l}\text { Determinación indirecta } \\
\text { (accesibilidad, cercanía a los centros } \\
\text { poblados, incidencia de grandes } \\
\text { incendios, distribución de BN en el } \\
\text { área de concentración de la actividad } \\
\text { forestal). }\end{array}$ \\
\hline $\begin{array}{l}\text { 7. Potencial } \\
\text { forestal }\end{array}$ & No especificado & $\begin{array}{l}\text { Disponibilidad } \\
\text { actual BN; capacidad } \\
\text { productiva; tasa de } \\
\text { regeneración }\end{array}$ & No especificado & $\begin{array}{l}\text { Disponibilidad actual de BN, } \\
\text { renovales de especies valiosas; } \\
\text { clases y estructura de la vegetación; } \\
\text { pedidos de aprovechamiento }\end{array}$ \\
\hline $\begin{array}{l}\text { 8. Potencial de } \\
\text { sustentabilidad } \\
\text { agrícola }\end{array}$ & No especificado. & $\begin{array}{l}\text { Variabilidad de } \\
\text { precipitación.; capacidad } \\
\text { de uso del suelo; riesgo } \\
\text { agroclimático; aptitud } \\
\text { del uso del suelo; índice } \\
\text { de productividad }\end{array}$ & No especificado & $\begin{array}{l}\text { Productividad del suelo, } \\
\text { pendiente del terreno y rangos de } \\
\text { precipitación. }\end{array}$ \\
\hline $\begin{array}{l}\text { 9. Potencial de } \\
\text { conservación de } \\
\text { cuencas }\end{array}$ & $\begin{array}{l}\text { Zonas de } \\
\text { especial interés }\end{array}$ & $\begin{array}{l}\text { Protección: bordes de } \\
\text { ríos, cuerpos de agua y } \\
\text { sitios RAMSAR. }\end{array}$ & $\begin{array}{l}\text { Bosques en } \\
\text { galería }\end{array}$ & Estado de la cuenca \\
\hline $\begin{array}{l}\text { 10. Valor que las } \\
\text { Comunidades } \\
\text { Indígenas y } \\
\text { Campesinas dan } \\
\text { a los BN }\end{array}$ & $\begin{array}{l}\text { No especificado. } \\
\text { Uso } \\
\text { relevamiento } \\
\text { técnico }\end{array}$ & $\begin{array}{l}\text { Áreas de pertenencia } \\
\text { aborigen }\end{array}$ & $\begin{array}{l}\text { Títulos de } \\
\text { propiedad }\end{array}$ & Informes y reclamos territoriales \\
\hline
\end{tabular}

AP: Áreas protegidas; BN: Bosques nativos 
y Agroindustrias (UNSE), la Universidad Católica de Santiago del Estero, el Instituto Nacional de Tecnología Agropecuaria y el Consejo Profesional de Ingeniería y de la Arquitectura. En Chaco la autoridad es la Subsecretaría de Recursos Naturales y Medio Ambiente dependiente del Ministerio de la Producción del Gobierno de la Provincia del Chaco opera a través de la Dirección de Bosques. La Subsecretaría de Recursos Naturales Ordenamiento y Calidad Ambiental está a cargo de aplicar la ley en Formosa. En Salta opera una Agencia de Bosques Nativos a través del Ministerio de Ambiente y Desarrollo Sustentable.

En todas las provincias, y como indica la ley, la categoría I (roja) no puede transformarse. Sin embargo, se encontraron discrepancias en cuanto al nivel de transformación del bosque permitido en las categorías II (amarilla) y III (verde) (Tabla 3). En la categoría II, Chaco y Santiago del Estero han flexibilizado los usos permitidos dentro de estas áreas admitiendo cambios de uso del suelo y aprovechamiento silvopastoril, reduciendo la superficie destinada a la conservación y manejo sostenible a un porcentaje menor al $50 \%$ de lo asignado inicialmente.

En la categoría III, Formosa resultó más estricta en cuanto al porcentaje de transformación permitido ya que establece un valor según la zona de ordenamiento territorial y el grupo fisonómico involucrado. Aunque también es la provincia que incluye una mayor proporción de sus bosques en esta categoría $(74 \%)$. Además, Formosa ha implementado diversos mecanismos de flexibilización como Canjes de Permiso de Cambio en el Uso del Suelo y Programas de Interés Estratégico. El primero es un mecanismo de intercambio comercial que permite aumentar las superficies a habilitar en un predio, a cambio de una reducción equivalente en otro $u$ otros predios. El segundo es una serie de programas estatales que permiten aumentar las superficies del predio susceptibles de cambio de uso del suelo. En Chaco a mayor superficie predial, mayor será el área a conservar como clausura

Tabla 5. Listado de los criterios de sustentabilidad especificados dentro de la ley 26331 y la comparación relativa del nivel de consideración de los mismos realizado en cada provincia.

Table 5. Listing of the sustainability criteria specified in the law 26331 and the relative comparison of their level of consideration performed in each province.

\begin{tabular}{|c|c|c|c|c|c|c|c|}
\hline Criterio de Sustentabilidad Ambiental & $\begin{array}{l}\text { Santiago } \\
\text { del Estero }\end{array}$ & Chaco & Formosa & Salta & $\begin{array}{l}\text { Total de } \\
\text { letras A }\end{array}$ & $\begin{array}{l}\text { Total de } \\
\text { letras B }\end{array}$ & $\begin{array}{l}\text { Total de } \\
\text { letras C }\end{array}$ \\
\hline 1. Superficie & $\mathrm{C}$ & B & $\mathrm{C}$ & A & 1 & 1 & 2 \\
\hline 2. Vinculación con otras comunidades naturales & $\mathrm{C}$ & A & B & A & 2 & 1 & 1 \\
\hline $\begin{array}{l}\text { 3. Vinculación con áreas protegidas existentes e } \\
\text { integración regional }\end{array}$ & $\mathrm{C}$ & A & $\mathrm{C}$ & A & 2 & 0 & 2 \\
\hline 4. Existencia de valores biológicos sobresalientes & $\mathrm{C}$ & A & B & A & 2 & 1 & 1 \\
\hline 5. Conectividad entre ecorregiones & B & B & B & B & 0 & 4 & 0 \\
\hline 6. Estado de conservación & $\mathrm{C}$ & $\mathrm{C}$ & $\mathrm{C}$ & A & 1 & 0 & 3 \\
\hline 7. Potencial forestal & $\mathrm{C}$ & A & C & A & 2 & 0 & 2 \\
\hline 8. Potencial de sustentabilidad agrícola & C & A & $\mathrm{C}$ & B & 1 & 1 & 2 \\
\hline 9. Potencial de conservación de cuencas & B & B & $\mathrm{C}$ & A & 1 & 2 & 1 \\
\hline $\begin{array}{l}\text { 10. Valor que las Comunidades Indígenas y } \\
\text { Campesinas dan a los BN }\end{array}$ & $\mathrm{C}$ & B & $\mathrm{C}$ & A & 1 & 1 & 2 \\
\hline Total de letras A & 0 & 5 & 0 & 8 & & & \\
\hline Total de letras B & 2 & 4 & 3 & 2 & & & \\
\hline Total de letras C & 8 & 1 & 7 & 0 & & & \\
\hline Superficie de la provincia bajo categoría I (\%) & 7.6 & 2.9 & 5.6 & 8.3 & & & \\
\hline $\begin{array}{l}\text { Superficie de categoría I no contemplada en } \\
\text { legislación preexistente }(\%)\end{array}$ & 0 & 77.6 & 71 & 82.7 & & & \\
\hline Superficie boscosa bajo categoría I (\%) & 14 & 6 & 9 & 16 & & & \\
\hline Superficie boscosa bajo categoría II (\%) & 74 & 63 & 16.5 & 65 & & & \\
\hline Superficie boscosa bajo categoría III (\%) & 12 & 31 & 74.5 & 19 & & & \\
\hline Superficie no boscosa (\%) & 43.9 & 50.6 & 39.1 & 46.7 & & & \\
\hline
\end{tabular}

$\mathrm{A}>\mathrm{B}>\mathrm{C}$ : nivel de detalle relativo de las 4 provincias en función a la información que contienen los informes. 
o reserva. Las clausuras incluyen actividades de la clase II como silvopastoriles; las reservas incluyen barreras forestales e implantación de especies nativas. En Santiago del Estero también debe conservarse cierto porcentaje del predio bajo macizo forestal. En Salta, si bien pueden transformarse las áreas asignadas a la Categoría II, existen ciertas restricciones para zonas que presentan limitaciones edáficas, que deben ser consideradas en la Evaluación de Impacto Ambiental (Tabla 3).

\section{Implementación de los criterios de OTBN}

El anexo de la ley 26331 describe los criterios de sustentabilidad ambiental a considerarse para el desarrollo del OTBN (Tablas 1, 4). Los informes presentan grandes diferencias en cuanto al nivel de detalle con el que se indica la manera en la que se aplicaron los criterios y la información usada (ver Apéndice II, donde figuran referencias bibliográficas de los informes de OTBN), respondiendo a las dos primeras preguntas planteadas en la introducción. Formosa y Santiago del Estero no describen cómo han sido tomados en cuenta estos criterios, dificultando la comparación y evaluación de los resultados. El informe de Santiago del Estero se basa en la compatibilización entre la Ley Nacional 26331 y la Ley Provincial de Conservación y Uso Múltiple de áreas Forestales de Santiago del Estero 6841/06, que se basa en criterios y variables principalmente productivos. Formosa parte de la compatibilización del programa de Ordenamiento Territorial de la Provincia, Ley Provincial 1552/2011 (POTFor) con la Ley 26331 en áreas boscosas. Consideramos de manera comparativa la interpretación de cada criterio en las distintas provincias (Tabla 4, Apéndice III). Cabe aclarar que se intentó recuperar material adicional que permitiera rastrear las razones técnicas de tales criterios, contactando a las autoridades provinciales y entrevistando a miembros de la autoridad nacional.

La Tabla 5 sintetiza la exhaustividad con la que se ha considerado cada criterio, según la información que contienen los informes de OTBN, asignando valores en una escala de tres niveles (A, B y C). Siendo A el de mayor nivel de detalle de información relativo y $\mathrm{C}$ el de menor. Cabe aclarar, que el empleo de A no significa que el nivel de detalle usado es el adecuado desde el punto de vista técnico, sino que simplemente fue el mayor encontrado para las provincias analizadas. La asignación del nivel A tuvo en cuenta el sustento técnico de los criterios, el cuál involucra no sólo la información utilizada para su determinación, sino también metodología de valorización y ponderación ó de asignación a categorías específicas. El nivel B, a diferencia del anterior, no describe metodologías de ponderación, o los criterios son considerados de manera incompleta. El nivel C, no presenta la metodología o bibliografía que respalde la asignación de los bosques a determinada categoría de conservación o su consideración se aleja de la definición establecida a nivel nacional.

Adicionalmente se detalla qué porcentaje ocupan las categorías I, II y III, que porcentaje de la superficie provincial resulta no bosque, cuánto representa la categoría I de la superficie provincial y que porcentaje de la categoría I no había sido antes contemplado como valioso (sectores no contemplados en legislación preexistente). Salta y Chaco consideraron mayor nivel de detalle relativo en los 10 criterios de sustentabilidad (8A y $2 \mathrm{~B}$ para Salta y $5 \mathrm{~A}, 4 \mathrm{~B}$ y $1 \mathrm{C}$ para Chaco) (Tabla 5), mientras que Santiago del Estero y Formosa utilizaron información con un nivel de detalle menor ( $8 \mathrm{C}$ y $2 \mathrm{~B}$ para Santiago del Estero y 3B y 7C para Formosa). Si se analiza el nivel de detalle utilizado para cada criterio, independientemente de la provincia, se puede observar que el menor nivel de detalle se presenta para el criterio "estado de conservación", seguido por "superficie" y "valor que las Comunidades Indígenas y Campesinas dan a los BN". Solamente en el criterio "conectividad entre ecorregiones"

Tabla 6. Pruebas de bondad de ajuste parciales para cada uno de los cinco pares de provincias colindantes analizadas. Dónde: $\mathrm{O}_{i}$ : frecuencia absoluta del valor observado del Índice I; E: frecuencia esperada de valores del Î́ndice I; gl: grados de libertad; Vc: valor crítico. La última columna corresponde al estadístico de Pearson que se compara con el valor crítico.

Table 6. Partial goodness of fit tests applied to the five neighbor provinces analyzed. Where: $\mathrm{O}_{\mathrm{i}}$ : absolute frequency of the observed value of the I Index, $\mathrm{E}_{i}$ : expected frequency of the I Index values, gl: degrees of freedom, Vc: critical value. The last column corresponds to the Pearson statistic, which is compare with the critical value.

\begin{tabular}{llllllllll}
\hline \multicolumn{1}{c}{$\begin{array}{l}\text { Cola } \\
\text { Izquierda }\end{array}$} & \multicolumn{1}{c}{ Cero } & \multicolumn{7}{c}{$\begin{array}{l}\text { Cola } \\
\text { Derecha }\end{array}$} \\
& $\mathrm{O}_{\mathrm{i}}$ & $\mathrm{E}_{\mathrm{i}}$ & $\mathrm{O}_{\mathrm{i}}$ & $\mathrm{E}_{\mathrm{i}}$ & $\mathrm{O}_{\mathrm{i}}$ & $\mathrm{E}_{\mathrm{i}}$ & $\mathrm{N}$ & $\begin{array}{l}\text { Est. } \\
\text { Pearson }\end{array}$ \\
1-StCh & 42 & 9 & 126 & 162 & 12 & 9 & 180 & 130 \\
2-ChFo & 29 & 4.4 & 35 & 79.2 & 24 & 4.4 & 88 & 249.5 \\
3-FoSa & 1 & 3.5 & 19 & 63.9 & 51 & 3.5 & 71 & 667.6 \\
4-ChSa & 65 & 4.6 & 26 & 82.8 & 1 & 4.6 & 92 & 834.8 \\
5-StSa & 57 & 2.9 & 1 & 52.2 & 0 & 2.9 & 58 & 1062.3 \\
\hline
\end{tabular}

gl: 2; Vc: 5.9 
las cuatro provincias utilizaron un nivel de detalle similar.

Con respecto a la composición de la categoría I, la provincia de Chaco incorpora dentro de esta exclusivamente parques nacionales, provinciales y reservas. A esto se suma una superficie de 223704 ha perteneciente a los lotes fiscales de Almirante Brown y Güemes que representan un $77.6 \%$ de esta categoría. En cuanto a los bordes de los ríos y cuerpos de agua, estos son clasificados como categoría II (Amarilla). Su inclusión dentro de esta categoría los habilita a ser aprovechados forestalmente o a producir madera. Salta por su parte, dentro de esta categoría sólo un 17.3\% corresponden a áreas de protección nacional y provincial, el $82.7 \%$ restante corresponde a diversas áreas de especial interés (un 63.4\% a Corredores riparios y Humedales, un $0.4 \%$ de Protección Privada y un $18.9 \%$ son Áreas prioritarias de TNC). Formosa incorpora en esta categoría a las áreas protegidas estrictas, representando un $29 \%$ y aquellos bosques ubicados sobre los albardones en la zona productiva Litoral, y los márgenes de los ríos, que corresponden al $71 \%$ restante, no contemplado en la legislación preexistente. Por su parte, Santiago del Estero incluye dentro de esta categoría las áreas protegidas nacionales y provinciales, y sectores que no podían ser transformados porque tenían carácter de protector en la Ley Provincial 6841 de Conservación y Uso Múltiple de las Áreas Forestales. Con lo cual, la superficie
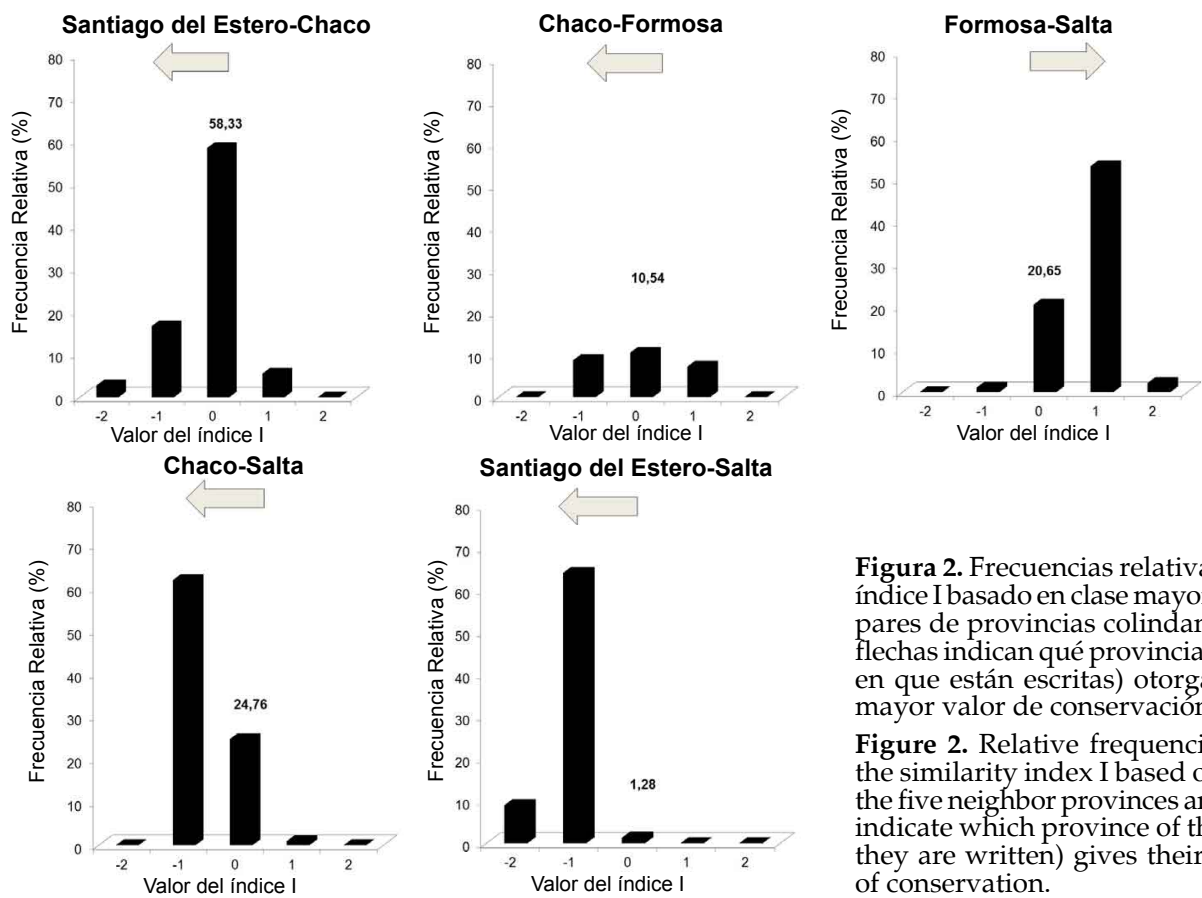

Figura 2. Frecuencias relativas de los valores del índice I basado en clase mayoritaria para los cinco pares de provincias colindantes analizadas. Las flechas indican qué provincia del par (en el orden en que están escritas) otorga a sus bosques un mayor valor de conservación.

Figure 2. Relative frequencies of the values of the similarity index I based on majority class for the five neighbor provinces analyzed. The arrows indicate which province of the pair (in the order they are written) gives their forest higher level of conservation. 
Salta. A su vez, Chaco otorgó mayor valor a sus bosques que Formosa y Salta, y entre estas dos últimas provincias, Salta fue la que otorgó un mayor valor a sus bosques (Figura 2).

Otra cuestión importante de considerar es el mapa forestal de base empleado para la zonificación. Formosa elaboró ese mapa considerando la información surgida de los mapas de clima, hidrología, geomorfología y aptitud de suelos. Chaco consideró el Inventario Forestal de la Provincia del Chaco (2005), mientras que Santiago del Estero utilizó el Inventario Nacional de Bosques Nativos de la SAyDS (2005) y Salta empleó métodos complementarios, de interpretación visual y clasificación digital de imágenes. La Resolución COFEMA 230/ 2012 deja constancia de que al comparar los mapas de bosque nativo realizados por las provincias con datos de referencia (Primer Inventario Nacional de Bosques Nativos y sus actualizaciones cartográficas) existen áreas boscosas que no fueron incluidas en el OTBN, quedando invisibilizadas y no legisladas. Por el contrario, áreas que no se enmarcan en la definición de bosque nativo, fueron incorporadas por interdependencia funcional con los bosques.

\section{DISCUSIÓN Y CONSIDERACIONES FINALES}

La Ley 26331 representa un enorme avance para la protección del bosque nativo en Argentina. La sanción de esta ley instaló la necesidad del Ordenamiento Territorial en los sistemas políticos provinciales y en la opinión pública, fijando un piso para nuevas alternativas de planificación que contemplen las dimensiones sociales, culturales, económicas y ambientales. Los análisis realizados sobre los productos del proceso de OTBN en Santiago del Estero, Formosa, Chaco y Salta en el marco de la Ley 26331 permitieron determinar, no obstante, que el grado de acuerdo entre provincias vecinas resulta escaso.

Por un lado, y en relación con las dos primeras preguntas planteadas en la introducción, la información utilizada y la interpretación de los criterios de sustentabilidad establecidos por la ley ha sido dispar entre provincias. Esto podría estar asociado a las capacidades del equipo técnico, a diferentes influencias de grupos de presión, a la disponibilidad de información, a la forma en que son descriptos los criterios en la ley, a las discrepancias en el nivel de percepción del territorio, entre otros factores. En cuanto al nivel de percepción del territorio, no puede determinarse la escala empleada para cada criterio por falta de información. Pero se observa que las clasificaciones realizadas por las provincias han sido presentadas en una escala 1:250000, a excepción de Santiago del Estero que presenta su cartografía en una escala de 1:350000. Una escala 1:250000 se correspondería con una unidad mínima de mapeo (resolución espacial) de 25 hectáreas. Si bien esta escala constituye un requisito técnico de representación cartográfica, no se corresponde con la escala de trabajo mínima. La ley establece una excepción en la aplicación de la ley únicamente en superficies menores a 10 hectáreas que sean de propiedad de comunidades indígenas o pequeños campesinos. Por otra parte, no pueden descartarse disputas y presiones políticas que no se hacen explícitas en los planteos técnicos, como por ejemplo las señaladas por Seghezzo et al. (2011) para el caso de Salta.

En relación a las preguntas 3 y 4, nuestros resultados indican fuertes discrepancias en cuanto a la zonificación realizada por cada provincia. Esto concuerda con lo destacado por La Red Agroforestal Chaco Argentina (REDAF). En vista de las diferencias existentes entre los planes de OTBN desarrollados, esta ONG ha elaborado una serie de informes sobre el panorama de los OTBN en la región Chaqueña analizando los puntos geográficos con mayores discrepancias de categorización (REDAF 2009). Estas diferencias pueden tener causas legítimas (visiones distintas por parte de los distintos gobiernos provinciales; diferencias en las características biofísicas y humanas a ambos lados del límite; contextos socio- cultural, económicos o de conservación diferentes) pero también pueden ser el resultado de una inadecuada caracterización de los criterios establecidos por la ley. Lamentablemente varios de los informes provinciales omiten las evidencias y modelos conceptuales en los que apoyan las decisiones. Más aún, el peso relativo de cada uno de los criterios y los umbrales a partir de los cuales un área es asignada a una $u$ otra categoría (Somma et al. 2011) no son explícitos en ningún caso. Sin duda este es un aspecto a revisar en futuras re-zonificaciones o en el proceso de re-categorización. Una definición más transparente del proceso de asignación de clases de conservación es un paso crítico para la legitimación social de los mapas provinciales de OTBN.

La Ley de OTBN es reciente, incluso algunas provincias no han realizado o acreditado ante la SAyDS aún la zonificación (enero 2013). La 
falta de un protocolo de trabajo estandarizado y consensuado junto con el bajo nivel de acuerdo en las zonificaciones provinciales ha conducido a una desarticulación a nivel regional, agudizada frente a la interpretación dispar de los criterios de sustentabilidad ambiental y las diversas modalidades de aplicación de la ley. Los resultados del análisis de la concordancia en la categorización de los bosques muestran que las zonificaciones de la región Chaqueña no han resultado consistentes entre provincias, evidenciándose diferencias significativas entre las categorías de conservación asignadas en todos los distintos pares de provincias colindantes analizadas. Es importante considerar que la reglamentación de la ley establecida en el decreto 91/2009 establece que las autoridades locales de aplicación, que aprueben por ley su Ordenamiento de BN, deberán remitir información referida al nivel de coherencia de sus categorías de conservación con respecto a las de las provincias limítrofes que hayan aprobado por ley su Ordenamiento. La ley indica también que la autoridad nacional de aplicación junto al Consejo Federal de Medio Ambiente (COFEMA) deberá promover acciones tendientes a lograr un nivel de coherencia entre las categorías de conservación en aquellas jurisdicciones que comparten ecorregiones. La resolución 229/ 2012 del COFEMA (posterior a buena parte de las leyes de OT provinciales) hace expresa mención a la diversidad de situaciones en cuanto a la implementación de la ley de OTBN, con jurisdicciones que han avanzado significativamente en su ordenamiento e instrumentación y otras que aún se encuentran en estado incipiente. Establece una serie de lineamientos básicos para la presentación de los planes de OTBN, entre lo que sugiere incluir las coberturas digitales utilizadas, el mapa con las categorías asignadas, y un informe final detallando la metodología utilizada para la valoración de los criterios y asignación de las categorías de conservación, indicando la fuente de información utilizada y documentación que muestre la coherencia de categorías de conservación de bosques con las de provincias vecinas, entre otras cuestiones.

La Ley 26331 introduce el mecanismo de compensación por servicios ambientales (o servicios ecosistémicos, más propiamente). Este es el primer antecedente en la legislación argentina de uso del concepto de servicios ecosistémicos y uno de los pocos a nivel latinoamericano (Balvanera et al. 2012). Acuerdos como la Convención Marco sobre el Cambio Climático y el Convenio sobre Diversidad Biológica señalan líneas que dan sustento político-técnico al desarrollo de iniciativas innovadoras respecto a lo de los servicios ecosistémicos, su valoración monetaria y a su conservación. Ejemplos de ellos son la mitigación de las emisiones de gases con efecto invernadero, la conservación de la biodiversidad, el mantenimiento de la calidad y cantidad de agua (protección de recursos hídricos) y la protección de la belleza escénica.

Sin embargo, el foco en la Ley 26331 está puesto en un posible mecanismo de compensación por la pérdida de servicios ecosistémicos y no en la determinación de cambios en su nivel de provisión. La ley de OTBN identifica pobremente los servicios ecosistémicos que brindan los bosques ya que no los define de manera explícita ni avanza en su cuantificación. La caracterización de la pérdida en la provisión de varios de ellos está asociada a distintas transformaciones del territorio para los sistemas de bosques xerofíticos de la región chaqueña ha sido estudiada en una cantidad de trabajos (Paruelo et al. 2011; Viglizzo et al. 2011; Mastrangelo\&Gavin 2012; Volante et al. 2012). La falta de incentivos oficiales para su análisis e incorporación en la toma de decisiones retrasa el desarrollo de estrategias de mitigación o reversión. Para lograr una alternativa operativa que se incorpore en el proceso de toma de decisiones es necesario determinar las funciones de afectación de servicios ecosistémicos (la relación entre factores de estrés y perturbación y el nivel de provisión de servicios específicos), e identificar los actores e involucrados que resultan afectadores y beneficiarios de los servicios provistos por los bosques (Paruelo 2011; Viglizzo et al. 2012). La Ley 26331 y, consecuentemente, los informes provinciales analizados no consideran explícitamente el enfoque basado en la noción de servicios ecosistémicos a pesar de la importancia que supone este punto y el vínculo explícito de la ley con este concepto.

La sanción de la Ley de OTBN buscó promover un debate amplio y participativo respecto del ordenamiento territorial de los bosques, incorporando a actores excluidos del debate público (pueblos originarios, comunidades criollas y campesinas). Sin embargo, la incorporación de estos actores resultó incompleta en ciertos casos y disímil entre las provincias a pesar del énfasis de 
la ley en este punto. Un aspecto a tener en cuenta es el derecho a uso del territorio bajo uso tradicional de pueblos originarios que no necesariamente implica propiedad de la tierra. Hay una fuerte tendencia a aplicar a comunidades y usos tradicionales la lógica de propiedad de la tierra, mientras que los usos tradicionales justamente eran comunitarios sobre recursos sin propiedad o de libre acceso. Esto se refleja en el caso de Formosa, que sólo contempla aquellas comunidades con título de propiedad registrado en las oficinas de catastro, sin contemplar circuitos de uso de recursos (recolección de algarrobo, chaguar, acceso al río, etc.) que pueden incluir sectores de propiedades privadas. Estas actividades de uso tradicional no son incompatibles con manejo de bosque nativo pero sí son incompatibles si el bosque es convertido a usos agropecuarios (silvopastoril, pastoril o agrícola). De esta forma, no se permite considerar equitativamente las aspiraciones de los distintos grupos sociales sobre el territorio y su dotación de recursos naturales tal como lo establecen algunas leyes nacionales o convenios internacionales (particularmente la Ley Nacional 26160 de Emergencia Territorial Indígena y la Ley 24071, Convenio 169 dela OIT sobre pueblos indígenas y tribales). Esto lleva a restringir de manera creciente la capacidad de las comunidades aborígenes y campesinas de decidir acerca del uso de sus territorios. Grau y colaboradores (2011) afirman que una de las limitantes que enfrenta el OT en la Argentina es la dificultad de garantizar la participación e inclusión de los intereses de aquellos sectores de la sociedad más relegados o con menor poder de negociación.

Agradecimientos: A la Dirección de Bosques y a los gobiernos provinciales por facilitar el acceso a la información. Este trabajo se llevó adelante con el apoyo del subsidio CRN2031 y CRN3095 del Instituto Interamericano para la Investigación del Cambio Global (IAI), financiado por National Science Foundation. FONCYT, UBACYT y CONICET financiaron parcialmente este trabajo.

\section{BIBLIOGRAFÍA}

Aizen, MA; LA Garibaldi \& M Dondo. 2009. Expansión de la soja y diversidad de la agricultura argentina. Ecología. Austral, 19:45-54.

Balvanera, P; M Uriarte; L Almeida-Leñero; A Altesor; F DeCLERK; T GARDNER; ET AL. 2012. Ecosystem Services research in latin America: the state of the art. Ecosystem Services, 2:56-70.

B.O. $N^{\circ}$ 31595.2009. Ley de Protección ambiental de Bosques Nativos $\mathrm{N}^{\circ} 26331$. Primera sección. Argentina. 3 págs. En línea. [Consulta: 12 de abril de 2011]. Disponible en:<http:/ / www.boletinoficial.gov.ar/DisplayPdf.asp $\mathrm{x} ? \mathrm{~s}=\mathrm{BPBCF} \& \mathrm{f}=20090216>$.

DEVORE,JL. 2003. Probabilidad y estadística para ingeniería y ciencias. 5ta. Edición. International Thomson Editores, S. A.

Grau, R; M Aide \& I Gasparri. 2005. Globalization and soybean expansion into semiarid ecosystems of Argentina. Ambio, 34:265-266.

Grau, H; N Gasparri \& M Gasparri. 2011. Cambio y eficiencia de uso del territorio en el Chaco argentino: el conflicto entre producción de alimentos y conservación de la naturaleza en distintas escalas. [Capítulo 17]. En: Laterra, P; EG Jobbágy \& JM PARUelo (eds.). Valoración de Servicios Ecosistémicos: Conceptos, herramientas y aplicaciones para el ordenamiento territorial. MAGyP.

Mastrangelo, ME \& MC Gavin. 2012. Trade-offs between cattle production and bird cosnervation in an agricultural. Conservation Biology, 26:1523-1739.

Paruelo, JM; JP Guerschman \& SR Verón. 2005. Expansión agrícola y cambios en el uso del suelo. Ciencia Hoy, 15:14-23.

Paruelo, JM. 2011. Valoración de Servicios Ecosistémicos y Planificación del Uso del Territorio ¿Es necesario hablar de dinero? [Capítulo 5]. En: LaterRa, P; EG JobBÁGY \& JM PARuelo (eds.). Valoración de Servicios Ecosistémicos: Conceptos, herramientas y aplicaciones para el ordenamiento territorial. MAGyP.

Paruelo, JM; D Alcaraz Segura \& JN Volante. 2011. El seguimiento del nivel de provisión de los servicios ecosistémicos. [Capítulo 6]. En: LATERra, P; EG JobBÁGY \& JM Paruelo (eds.). Valoración de Servicios Ecosistémicos: Conceptos, herramientas y aplicaciones para el ordenamiento territorial. MAGyP.

Red Agroforestal Chaco Argentina (REDAF). 2009. Ley de Bosques: Panorama en la Región Chaqueña Argentina Panorama en la Región Chaqueña Argentina. Tercer Informe de Monitoreo Red Agroforestal Chaco Argentino.

SeghezZO, L;JN Volante;JMParuelo; DJ SOMma; EC BULLUbasich; HE RODRíGUEZ; ET AL. 2011. Native Forests and Agriculture in Salta (Argentina): Conflicting Visions of Development. Journal of Environment \& Development, 20:251-277.

Somma, D; J Volante; L LizÁrRaga; M Boasso et al. 2011. Aplicación de análisis multicriterio multiobjetivo como base de un sistema espacial de soporte de decisiones para la planificación del uso sustentable del territorio en regiones forestales. Caso de estudio: los bosques nativos de la provincia de salta. [Capítulo 18].En: LATERRA, P; EG JobBágy \& JM Paruelo (eds.). Valoración de Servicios Ecosistémicos: Conceptos, herramientas y aplicaciones para el ordenamiento territorial. MAGyP.

Unidad de Manejo del Sistema de Evaluación Forestal (UMSEF). 2007. Monitoreo de Bosque Nativo, Período 19982002 y Período 2002-2006 (Datos Preliminares). SAyDS \& UMSEF. [Argentina. 11pp.]

Viglizzo, EF; L Carreño; J Volante \& M Mosciaro. 2011. Valuación de bienes y servicios ecosistémicos: ¿verdad objetiva o cuento de la buena pipa? [Capítulo 1].En: LATERRA, P; EG Jobbágy \& JM PARUELo (eds.). Valoración de Servicios Ecosistémicos: Conceptos, herramientas y aplicaciones para el ordenamiento territorial. MAGyP.

Viglizzo, EF; JM Paruelo; P Laterra \& EG Jobbágy. 2012. Ecosystem service evaluation to support land-use policy. Agriculture, Ecosystems and Environment, 154:78-84.

Volante, JN; AR Bianchi; HP PaOli; YE NoÉ \& HJ Elena. 2006. Dinámica del Uso del Suelo Agrícola del Noroeste Argentino Mediante Teledetección y SIG. Período 20002005. INTA. Argentina. 64 pp.

Volante, J; D Alcaraz-Segura; MJ Mosciaro; EF Viglizzo \&JM PARUELlo. 2012. Ecosystem functional changes associated with landclearing in NW Argentina. Agriculture, Ecosystem \& Environment, 154:12-22.

ZAK, M; M CABIDO \& J Hodgson. 2004. Do subtropical seasonal forest in the Gran Chaco, Argentina, have a future? Biological conservation, 120:589-598. 


\section{INFORMACIÓN SUPLEMENTARIA}

\section{APÉNDICE I}

En la ley se entiende por "Bosque Nativo" "al ecosistema forestal natural compuesto predominantemente por especies arbóreas nativas maduras, con diversas especies de flora y fauna asociadas, en conjunto con el medio que las rodea (suelo, subsuelo, atmósfera, clima, recursos hídricos), conformando una trama interdependiente con características propias y múltiples funciones, que en su estado natural le otorgan al sistema una condición de equilibrio dinámico y que brinda diversos servicios ambientales a la sociedad, además de los diversos recursos naturales con posibilidad de utilización económica". Quedan expresamente incluidos, los bosques nativos de origen primario (sin intervención humana), los bosques nativos de origen secundario (formados luego de un desmonte) y los bosques nativos resultantes de una recomposición o restauración espontánea.

\section{ApÉNDICE II}

Consejo Provincial de Bosques. 2008. Propuesta de Ordenamiento Territorial de los Bosques Nativos de la Provincia de Santiago del Estero. Informe Final. Ministerio de Producción, Recursos Naturales y Tierras. 56 pp. Sin publicar.

Dirección de Bosques de la Nación (SAyDS). 2012. Ordenamiento Territorial de los Bosques Nativos (OTBN). Información entregada por las provincias en cumplimiento de la Ley 26.331 de Presupuestos Mínimos de Protección Ambiental de los Bosques Nativos.

Ministerio de Ambiente y Desarrollo Sustentable de Salta. 2009. Plan de Ordenamiento Territorial de las Áreas Boscosas de la Provincia de Salta. 88 pp. Sin publicar.

Ministerio de la Producción y Ambiente de la Provincia DE Formosa. 2009. Programa de Ordenamiento Territorial de la Provincia de Formosa (POT-For) y sus modificaciones. 27 pp. Sin publicar

Subsecretaría de Recursos Naturales del Chaco. 2008. Propuesta de Ordenamiento Territorial de los Bosques Nativos de la Provincia del Chaco. Ministerio de Economía, Producción y Empleo de la Provincia del Chaco. 35 pp. Sin publicar.

\section{APÉNDICE III}

\section{Análisis comparado de la información contenida en los informes:}

1- Superficie: Chaco: Se considera que el tamañodelasáreas protegidas vigentesasegura la inclusión de hábitat para especies de fauna notable, amenazada o en vía de extinción (Ley provincial $\mathrm{N}^{\circ} 4.358$ ). La categoría II funciona como área de amortiguación. Mientras que la Categoría III no resulta un hábitat propicio por su elevado nivel de fragmentación. Salta: En esta provincia se considera precautoriamente que la conservación de grandes bloques (10.000-1.000.000 ha) interconectados garantiza la supervivencia de grandes animales (Bennet 2003). Santiago del Estero y Formosa: En ninguno de los casos se indica cómo ha sido considerado este criterio.

\section{2- Vinculación con otras comunidades} naturales: Chaco: Esta provincia utiliza gradientes ecológicos determinados por la presencia de aves como indicadoras de biodiversidad en general junto con sitios de importancia para la conservación de animales mayores y menores dado que utilizan distintos ecosistemas en distintas épocas del año (FVSA et al. 2005; Aves Argentinas \& Asociación Ornitológica del Plata 2007). Salta: Se considera la vinculación de un área de bosque con otros pisos altitudinales de Yungas y la vinculación entre sectores latitudinales de Yungas a través del Chaco Serrano y Chaco Seco. Esto permitirían la conexión entre poblaciones de los distintos sectores (Brown et al. 2002; Brown \& Malizia 2004). Formosa: En este caso no se detalla cómo ha sido considerado este criterio pero se menciona que se utilizó la propuesta de corredores diseñada por técnicos de Parques Nacionales para garantizar conectividad entre ambientes naturales (APN et al. 2007). Santiago del Estero: En la ley de esta provincia no especifica cómo ha sido tenido en cuenta este criterio.

3- Vinculación con AP e integración regional: Chaco: Se considera la presencia de especies amenazadas de extinción y monumentos naturales provinciales (Ley provincial $\mathrm{N}^{\mathrm{o}} 4.306$ ) y la creación de corredores biológicos que incluya una vinculación entre áreas protegidas (FVSA et al. 2005; APN et al. 2007; Ley $\mathrm{N}^{\mathrm{o}}$ 4.358). Salta: La zonificación de esta provincia toma en cuenta las áreas protegidas nacionales como provinciales en su jurisdicción y establece una franja amarilla de amortiguamiento de 1 kilómetro alrededor de estas. Formosa: La propuesta de corredores de Administración de Parques Nacionales (2007) es la base para la aplicación de este criterio. Las modificaciones del informe de OTBN (i.e. Modificaciones del POT-For con expresión cartográfica realizadas a partir de las propuestas realizadas entre el 21/12/09 y el 29/03/10) incluyen áreas tampón y de transición en reservas pero no menciona especificaciones técnicas. Santiago del Estero: Se indica que las áreas protegidas (categoría I) se encuentran conectadas con bosques de la 
categoría II pero no menciona de qué forma ha sido determinado.

4- Existencia de valores biológicos sobresalientes: Chaco: En la zonificación se considera la presencia de aves como indicadores de biodiversidad en general, especies amenazadas de extinción, monumentos naturales provinciales (Ley $\mathrm{N}^{\circ}$ 4.306) y a su vez una serie de áreas prioritarias para la conservación (FVSA et al. 2005; Aves Argentinas y Asociación Ornitológica del Plata 2007). Salta: Se enumera una serie de elementos o sistemas de interés como: lagunas permanentes, madrejones, poblaciones de árboles viejos de especies de valor forestal, poblaciones de especies amenazadas, endemismos y sectores de palmares o de sabanas y utiliza distintos trabajos de investigación (Brown et al. 2002; Cristóbal et al. 2003; FVS 2005; Cristóbal 2006; Aves Argentinas y Asociación Ornitológicas del Plata 2007) para determinar su ubicación. Formosa: Se zonifica su provincia en dos grandes zonas (Corredores y CentralOriental) y establece porcentajes máximos de transformación de vegetación natural en zonas de categoría III (verde) privilegiando la conservación del patrimonio forestal -en especial los Bosques Altos- e incorpora una propuesta de Corredores de Conservación de Parques Nacionales (APN et al. 2007). Santiago del Estero: Se considera que las áreas de las grandes cuencas de los ríos Salado, Dulce y Horcones permiten el desplazamiento de la biodiversidad, por lo cual deben ser preservadas en todo proyecto. Dentro de la categoría III establece que un $30-40 \%$ de esas zonas han de permanecer en forma de macizos para su preservación pero no detalla los elementos que le han permitido arribar a estos resultados. Además hace hincapié en la necesidad de realizar estudios de la distribución de la biodiversidad a fin de crear reservas.

5- Conectividad entre ecorregiones: Chaco: Se define una franja de selva de ribera de 100 metros a cada lado de márgenes de ríos primarios y de 30 metros en ríos secundarios a la categoría I (Rohrmann et al. 2008). Salta: Se propone la preservación de corredores boscosos que conecten las Yungas con áreas de Chaco y permitan el desplazamiento de especies de aves y mamíferos entre ambas unidades ambientales. Las áreas asociadas a la Reserva de Pizarro y del Corredor del Itiyuro son prioritarias (Brown \& Pacheco 2006). Sin embargo el corredor de Itiyuro ha sido incluido en la categoría II. Formosa: Se consideran de especial interés los corredores riparios incorporando en la categoría I 500 metros a cada lado de márgenes de ríos principales y 100 metros en márgenes de ríos secundarios. Santiago del Estero: establece corredores riparios a ambos márgenes del río de 300 metros (Ley N $\mathrm{N}^{\circ}$ 2.852).

6- Estado de conservación: Salta: El estado de conservación se determina indirectamente utilizando la accesibilidad del área, cercanía a los centros poblados e incidencia de grandes incendios. También consideró la distribución de bosques nativos en el área de concentración de la actividad forestal (Morello et al. 2006). Chaco y Formosa: No se presenta información respecto a la consideración de este criterio. Santiago del Estero: Se menciona la utilización del Inventario forestal (SAyDS 2005) pero no se detalla cómo se determinó el estado de conservación.

7- Potencial forestal: Chaco: Para su estimación se considera la disponibilidad actual de recursos forestales analizando la cobertura de bosques nativos por departamento; la capacidad productiva según las clases o tipos forestales determinados en virtud del dosel y su proyección sobre el terreno; las especies principales y la tasa de regeneración para determinar el total de las existencias maderables y el volumen anual disponible (Cuello et al. 2000; Iza et al. 2005; Ley N ${ }^{\circ}$ 2.386). Salta: Considera para estimarlo la disponibilidad de recursos forestales, la estructura del bosque, la presencia de renovales de especies valiosas, las clases de vegetación y la ubicación de los pedidos de aprovechamiento otorgados por la provincia durante el período 2001-2006 (Morello et al. 2006; Badinier \& Eliano 2007). Formosa: No desarrolla la manera en la que se aplica este criterio este criterio y afirma que se mantendrán las normas de explotación forestal vigentes establecidas por las leyes provinciales y por la Dirección de Bosques de la Provincia. Santiago del Estero: No se específica en el informe cómo ha sido determinado el potencial forestal.

8- Potencial de sustentabilidad agrícola: Chaco: Se determina a partir de la aptitud del uso del suelo (en base a la textura, capacidad de retención de humedad y condiciones químicas adversas); el riesgo agroclimático (en base a sequías, inundaciones, anegamientos, suelos, vulnerabilidad de cultivos), el índice de productividad (vinculación de información edafoclimática y económica) y 
la variación interanual en las precipitaciones pluviométricas (Ledesma \& Zurita 1995; Ministerio de la Producción Chaco et al. 2005; Dirección de Suelos y Agua Rural 2008). Salta: Se considera el tipos de suelo, el Índice de Productividad (Atlas de suelos del INTA 1990), rangos de precipitaciones entre 1934-1990 (Bianchi et al. 2002) y la pendiente (Ley Provincial $\mathrm{N}^{\circ}$ 7.543). Formosa: No especifica cómo ha sido tenido en cuenta este criterio y menciona como objetivo favorecer la expansión de cultivos y pasturas sobre tierras de buenas condiciones productivas preservando bosques altos planteando escenarios de expansión posibles. Santiago del Estero: No específica como cómo ha sido tenido en cuenta este criterio.

\section{9- Potencial de conservación de cuencas:} Chaco: Se han identificado las cuencas hídricas y los cauces de ríos más importantes (Rohrmann et al. 2008). Se estableció la importancia de conservación de bordes de ríos, de cuerpos de agua permanentes y transitorios y de sitios RAMSAR bajo las categorías I y II. Salta: Se evaluó la condición de las cuencas teniendo en consideración su relación con las precipitaciones medias anuales (Bianchi et al. 2002), su nivel de desmonte y el nivel de pendiente para así determinar el umbral admisible de transformación de la vegetación natural. Formosa: Se le asigna especial interés a los bosques rip arios como ha sido mencionado en el criterio 5. Santiago del Estero: La zonificación consideró como áreas de especial interés para la conservación de cuencas áreas como bordes de salinas, lagunas saladas, lagos y lagunas permanentes, áreas de bañados y márgenes de ríos (zonas $\mathrm{E}, \mathrm{H}$ y $\mathrm{J}$ de la ley provincial $\mathrm{N}^{\mathrm{o}}$ 6.841).

10- Valor que las Comunidades Indígenas y Campesinas dan a los BN: Chaco: Considera áreas de pertenencia aborigen que consisten en tierras con título comunitario (Instituto de Colonización y Desarrollo Rural de Chaco 2008) y las reservadas bajo diferentes normativa (Ley $\mathrm{N}^{\circ} 26.160$, Convenio $\mathrm{N}^{\circ}$ 169 OIT).Salta: Toma en cuenta el informe generado por las ONGs Asociana, Tepeyac y Fundapaz (2008) para la región chaqueña donde se presenta un mapa de uso del espacio por comunidades indígenas del Chaco salteño y la ubicación de comunidades indígenas en el Departamento San Martín y Rivadavia; y el informe de García-Moritán (2008) del cual extrajo la ubicación de etnias para el sector de montaña yungueño. Por otro lado, también se hayan listados reclamos territoriales realizados de manera individual y conjunta. Formosa: Considera solo las comunidades aborígenes que tienen sus títulos de propiedad registrados en las oficinas de Catastro. Santiago del Estero: Se menciona el usode un relevamiento técnico y catastral de las tierras ocupadas por las comunidades indígenas pero no menciona como ha sido incorporado en el análisis (UNSE 2008).

\section{REFERENCIAS DE LOS APÉNDICES}

Administración de Parques Nacionales (APN); Provincia de Chaco \& Provincia de Formosa. 2007. Corredores de conservación: Puentes de vida con la gente. Corredores del Gran Chaco Argentino. Proyecto "Diseño de una estrategia regional de corredores de conservación del Gran Chaco Argentino".

Asociana; Tepec \& Fundapaz. 2008. Territorios indígenas y bosques nativos en el Chaco salteño. Delimitación de territorios indígenas a ser considerados en el proceso de Ordenamiento Territorial de la Provincia de Salta.

Aves Argentinas \& Asociación Ornitológica del Plata. 2007. Mapa de áreas de distribución de especies de fauna silvestre emblemática. Áreas importantes para la conservación de las aves en la Argentina-AICAS-. [Buenos Aires, Argentina].

Badinier, C \& P Eliano. 2007. Análisis de los proyectos de aprovechamiento forestal autorizados en Salta y Jujuy entre 2001 y 2006. Informe Fundación ProYungas.

BennetT, AF. 2003. Linkages in the Landscape: The Role of Corridors and Connectivity in Wildlife Conservation. IUCN. [Burwood, Australia. 262 pp].

Bianchi, AR; JN Volante; R Neumann; Y Noe \& AC GonZÁLEZ. 2002. Mapa digital de Isohietas Anuales del NOA. En línea. [Consultado 12 de agosto de 2011]. INTA EEA, Salta. Disponible en: <http://www.inta.gov.ar/ region/noa/prorenoa/info/resultados/Isohietas/ isoietas_anuales.htm>.

Brown, AD; A Grau; T Lomascolo \& NI Gasparri. 2002. Una estrategia de conservación para las selvas subtropicales de montaña (Yungas) de Argentina. Ecotrópicos 15:147-159.

BRown, AD \& LR MaLizia. 2004. Las Selvas Pedemontanas de las Yungas: En el umbral de la extinción. Ciencia Hoy 83:52-63.

BRown, AD \& S PACHECO. 2006. Propuesta de actualización del mapa ecorregional de la Argentina. En: BROWN, AD; U Martínez-Ortíz; M Acerbi \& J Corcuera. La Situación Ambiental Argentina. 2005. Fundación Vida Silvestre Argentina. Pp 28-31.

B.O. $\mathrm{N}^{\circ}$ 31595. 2009. Ley de Protección ambiental de Bosques Nativos N ${ }^{\circ}$ 26331. Primera sección. Argentina. 3 págs. En línea. [Consulta: 12 de abril de 2011]. Disponible en: <http://www.boletinoficial.gov.ar/DisplayPdf.asp $\mathrm{x} ? \mathrm{~s}=\mathrm{BPBCF} \& \mathrm{f}=20090216>$

CRISTÓBAL, LM; JP JAYAT; NI GASPARRI; T LOMASCOLO \& AD Brown. 2003. Humedales lenticos (lagunas y turberas) de las áreas montañosas del noroeste argentino. Seminario Internacional sobre manejo sustentable de humedales en América Latina. [Paraná, Argentina].

Cristóbal, L. 2006. Los Humedales de las Yungas. En: Brown AD, U Martínez-Ortíz, M Acerbi \& J Corcuera. 2005. La Situación Ambiental Argentina. Fundación Vida Silvestre Argentina. $58 \mathrm{pp}$. 
Cuello, R; ET AL. 2000. Mapa Forestal de la Provincia de Chaco. $1^{a}$ Etapa del Inventario Forestal del año 2000. Gobierno de la Provincia del Chaco y Cámara ArgentinoParaguaya de productores de Extracto de Quebracho.

Dirección de Suelos y Agua RuRal. 2008. Características Climáticas: Datos pluviométricos mensuales y anuales en la Provincia del Chaco (1956/57-2006/07). Mapa de isohietas medias anuales (1956-2007).

Fundación Vida Silvestre Argentina (FVSA); The Nature Conservancy (TNC); Fundación para el Desarrollo Sustentable del Chaco (Desdel Chaco) \& Wildife Conservation Society Bolivia (WCS). 2005. Evaluación Ecorregional del Gran Chaco Americano. Fundación Vida Silvestre Argentina. ISBN 950-9427-12-

Garcia-Moritán, M. 2008. La cara aborigen del alto Bermejo. Ciencia Hoy, Vol. 18.

Instituto de Colonización y Desarkollo Rural de la Provincia del CHACO. 2008. Información digital de las áreas provinciales de pertenencia aborigen. [Chaco, Argentina].

IzA, H; ET AL. 2005. Inventario Forestal Provincial del Ministerio de la Producción de la Provincia del Chaco 2005. Ministerio de la Producción de la Provincia del Chaco.

Ledesma, L \& J Zurita. 1995. Estudio e Inventario de Suelos del Chaco. Convenio INTA-Gobierno de la Provincia del Chaco.

Ministerio de la Producción del Chaco; INTA; Facultad de Ciencias Agrarias de la UNNE \& Administración Provincial del Agua. 2005. Mapa de Riesgo Agroclimático.

Morello, J; W Pengue \& AF Rodríguez. 2006. Etapas de uso de los recursos y desmantelamiento de la biota del Chaco. Pp 83-90 en: Brown AD, U Martínez Ortíz, M Acerbi \& J Corcuera.La Situación Ambiental Argentina. 2005. Fundación Vida Silvestre Argentina.

Rohrmann, H; J Peyrano \& J Parera. 2008. Hidrografía y Delimitación de Cuencas. Administración Provincial del Agua del Chaco.

Secretaria de Ambiente Desarrollo Sustentable (SAyDS). 2005. Primer Inventario Nacional de Bosques Nativos. Informe Regional Parque Chaqueño. Proyecto bosques nativos y áreas protegidas BIRF 4085-AR 1998-2001.

UNIVERSIDAD NACIONAL DESANTIAGO DEL ESTERO(UNSE). 2008. Relevamiento técnico, catastral y de la situación nominal de las tierras ocupadas por las comunidades indígenas en la provincia de Santiago del Estero. Instituto de Estudios Ambientales y Desarrollo Rural de la Llanura Chaqueña. 